\title{
Intelligent Controller for Reduction of Total Harmonics in Single Phase Inverters
}

\author{
Spencer Prathap Singh and Kesavan Nair \\ Department of Electrical and Electronics, Faculty of Electrical Engineering, \\ CSI Institute of Technology, Thovalai, K.K. Dist, Tamil Nadu, India
}

Received 2012-07-26, Revised 2013-05-14; Accepted 2013-09-18

\begin{abstract}
Due to the increased use of nonlinear loads, the problem of power harmonics becomes more and more complex. This work investigates the reduction of Harmonics in voltage controlled single phase full bridge inverter. The mapping state-space equations are generated by examining the single phase full bridge inverter. The PI and fuzzy logic controllers are used for the experimental simulation in this study. Experimental simulation clearly indicates that fuzzy logic controller reduces the total Harmonic distortion better than the conventional PI controller.
\end{abstract}

Keywords: Single-Phase Full-Bridge Inverter, PI Controller, FLC, THD, Load Variation

\section{INTRODUCTION}

Single-phase Inverters are generally used in the case of power failures, to deliver power to critical loads such as UPS, Induction heating, variable speed drives demand pure Sinusoidal voltage at the specified magnitude, frequency and low total harmonic distortion (Selvajyothi and Janakiraman, 2010). Normally DC-AC inverters which operate in Pulse Width Modulation (PWM) mode and switch between different circuit topologies introduce harmonics in the converter output (Hsieh et al., 2009).

In industries, the THD value should not exceed $5 \%$ as per the guidelines given in the IEEE standard, 519-1992 (Selvajyothi and Janakiraman, 2010). Many control techniques have been proposed for obtaining pure sinusoidal output with good voltage regulation and fast dynamic response (McNamara et al., 2007).

In the process of inversion in a thyristor converter system, harmonics as a function of power frequency are produced on both ac and dc side of the converter. Presence of harmonics in single phase inverters leads to number of disadvantages such as poor power factor, distortion, Interference, power loss to critical loads.
Recent studies on the complex behaviour of DC-AC inverters have generated number of conventional methods for reducing harmonics. However the inherently nonlinear characteristics of dc-ac converters have drawn great attention in research for applying nonlinear control principles for reducing total harmonics in single phase Inverters. This study aims to compare the performance of PI and fuzzy logic controllers for reducing harmonics in single phase inverters.

The nonlinear loads using power electronic devices increases harmonic pollution (Korimi-Ghartemani and Iravani, 2005; Zobaa, 2006). Harmonics due to nonlinear loads causes non sinusoidal voltages or currents in power converters (Moreno and Pigazo, 2007). The modulation techniques are commonly used to reduce low order harmonics (Villarreal-Ortiz et al., 2005).

Due to the rapid advancement of the Power electronics in industrial application makes industrial loads non-linear type. Non linear loads cause voltage and current distortions. Voltage harmonics depends on Source Stability and network impedance. Current harmonics are mainly load dependent. The Voltage and Current Waveforms may Consist of a Combination of the fundamental and Other frequencies (Moo et al.,

Corresponding Author: Spencer Prathap Singh, Department of Electrical and Electronics, Faculty of Electrical Engineering, CSI Institute of Technology, Thovalai, K.K. Dist, Tamil Nadu, India 
1995). The PWM scheme does not guarantee low distortion in the case of non-linear loads (Rahim and Quaicoe, 1996). An inductance-capacitance (LC) filter is connected in an inverter to minimize desired frequency components in the output waveforms (Rech et al., 2003). Implementation of State space control topology options in an inverter reduces harmonic distortion (Ryan et al., 1997). In an inverter a Sliding-Mode Control (SMC) Scheme is applied to deliver a.c power with low output voltage distortion as well as excellent voltage regulation under loading conditions (Tai and Chen, 2002).

\subsection{System Description of Single Phase Full Bridge Inverter}

The mathematical model for the voltage controlled single-phase full-bridge inverter based on bipolar voltage switching with Sinusoidal Pulse Width Modulation (SPWM) is considered here. It is assumed that all components are ideal. Figure $\mathbf{1}$ shows a schematic representation of the voltage controlled full-bridge inverter. In this system, the power circuit can generate a normal sinusoidal wave.

The power switches have two different topologies with control variable $\mathrm{U} €\{0,1\}$. If $\mathrm{TA}+$ and $\mathrm{TB}$ - are on then $\mathrm{U}=1$. If $\mathrm{TA}-$ and $\mathrm{TB}+$ are on then $\mathrm{U}=0$. Topology (1) $\mathrm{TA}+$ and TB-are on $(\mathrm{U}=1)$.

Based on SPWM, the system can generate positive half- sine wave for the load.

Figure 2 shows the equivalent circuit of Topology (1). The State space equation of the above equivalent circuit can be generated as follows.

Applying KVL Equation 1 and 2:

$$
\mathrm{V}_{\text {in }}=\mathrm{L}_{\mathrm{f}} \frac{\mathrm{di}_{\mathrm{Lf}}(\mathrm{t})}{\mathrm{dt}}+\mathrm{V}_{\mathrm{cf}}(\mathrm{t})
$$

$\frac{\mathrm{di}_{\mathrm{Lf}}(\mathrm{t})}{\mathrm{dt}}=\frac{\mathrm{V}_{\mathrm{in}}-\mathrm{V}_{\mathrm{cf}}(\mathrm{t})}{\mathrm{L}_{\mathrm{f}}}$

Also:

$$
\begin{aligned}
& i_{L f}(t)=i_{c f}(t)+i_{R}(t) i_{L f}(t)=C_{f} \frac{d v_{c f}(t)}{d t}+\frac{V_{c f}(t)}{R} \\
& \frac{d v_{c f}(t)}{d t}=\frac{i L_{f}(t)}{C F}-\frac{V_{c f}(t)}{R^{c} F}
\end{aligned}
$$

Topology (2): TA- and $\mathrm{TB}+$ are on $(\mathrm{U}=0)$.

Based on SPWM, the system can generate a negative half-sine wave for the load.

Figure 3 shows the equivalent circuit of Topology (2). The State space equation of the above equivalent circuit can be generated as follows.

Applying KVL Equation 3:

$V_{\text {in }}=L_{F} \frac{d_{i L} f(t)}{d t}+V_{c f}(t)$

$\frac{\mathrm{d}_{\mathrm{iLf}}(\mathrm{t})}{\mathrm{dt}}=-\frac{\mathrm{V}_{\mathrm{in}}-\mathrm{V}_{\mathrm{cf}}(\mathrm{t})}{\mathrm{L}_{\mathrm{f}}}$

Applying KCL Equation 4:

$\frac{\mathrm{dv}_{\mathrm{cf}}(\mathrm{t})}{\mathrm{dt}}=\frac{\mathrm{i}_{\mathrm{Lf}}(\mathrm{t})}{\mathrm{c}_{\mathrm{F}}}-\frac{\mathrm{V}_{\mathrm{cf}}(\mathrm{t})}{\mathrm{R}^{\mathrm{c}} \mathrm{F}}$

Equitation 1-4 are merged with controlled variables $\mathrm{U} €\{0,1\}$ into following Equation 5:

$\left(\begin{array}{c}\frac{\mathrm{di}_{\mathrm{Lf}}(\mathrm{t})}{\mathrm{dt}} \\ \frac{\mathrm{dV}_{\mathrm{cf}}(\mathrm{t})}{\mathrm{dt}}\end{array}\right)=\left(\begin{array}{cc}0 & \frac{-1}{\mathrm{~L}_{\mathrm{f}}} \\ \frac{1}{\mathrm{C}_{\mathrm{f}}} & \frac{-1}{\mathrm{R}_{\mathrm{cf}}}\end{array}\right)\left(\begin{array}{c}\mathrm{i}_{\mathrm{Lf}}(\mathrm{t}) \\ \mathrm{V}_{\mathrm{cf}}(\mathrm{t})\end{array}\right)+\left(\begin{array}{c}\frac{\mathrm{V}_{\text {in }}}{\mathrm{L}_{\mathrm{f}}} \\ 0\end{array}\right)(2 \mathrm{u}-1)$

Where:

$\mathrm{U}=$ Control Variable

$\mathrm{L}_{\mathrm{f}}=$ Filter inductance

$\mathrm{C}_{\mathrm{f}}=$ Filter Capacitance

$\mathrm{R}=$ Load resistance

$\mathrm{V}_{\text {in }}=\mathrm{Dc}$ input Voltage

\subsection{Model of PI control Strategy}

The Mathematical model of the single-phase fullbridge inverter is presented above (Hsieh et al., 2009). The MATLAB/SIMULINK tool is applied to simulate the SIMULINK model using PI controller. Table 1 shows the specifications of components used for Simulations.

The PI controller produces a control signal results from the combination of the proportional and the integral mode. The proportional plus integral controller produces an output signal as expressed below Equation 6:

$u(t)=K_{p} e(t)+K_{p} / T_{i} \int e(t) d t$ 


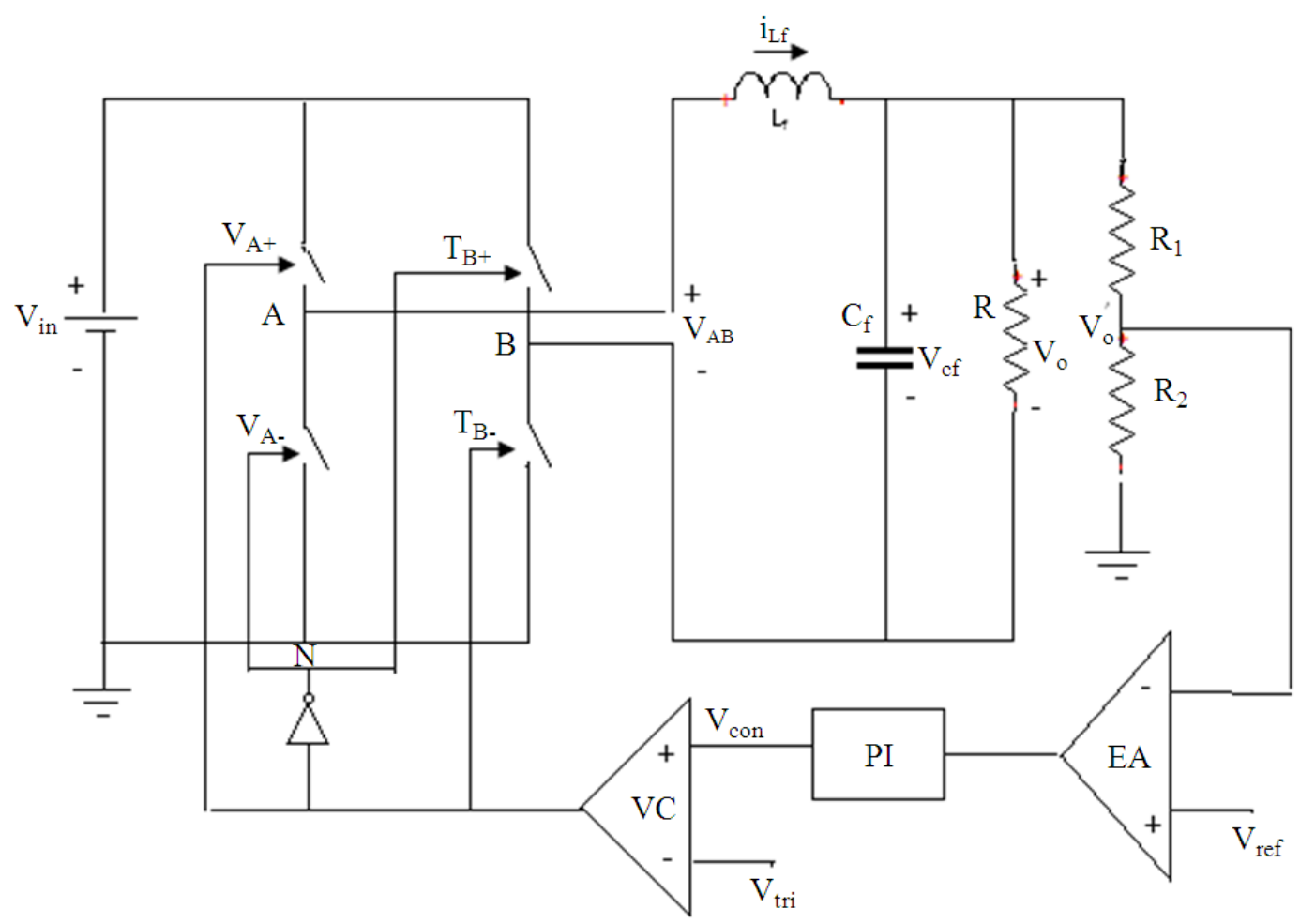

Fig. 1. Circuit of voltage-controlled single phase bridge inverter

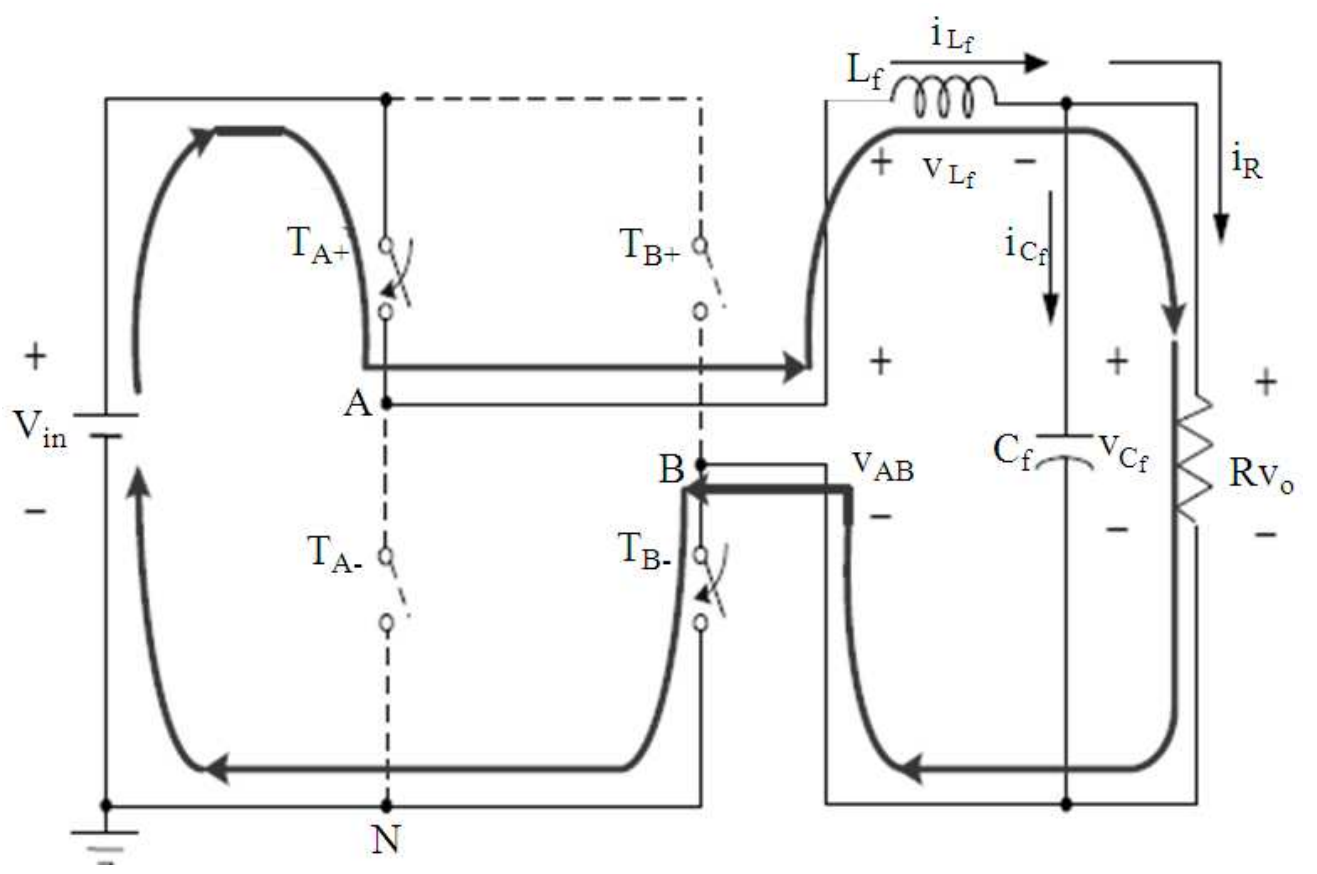

Fig. 2. Equivalent circuit of topology (1) 


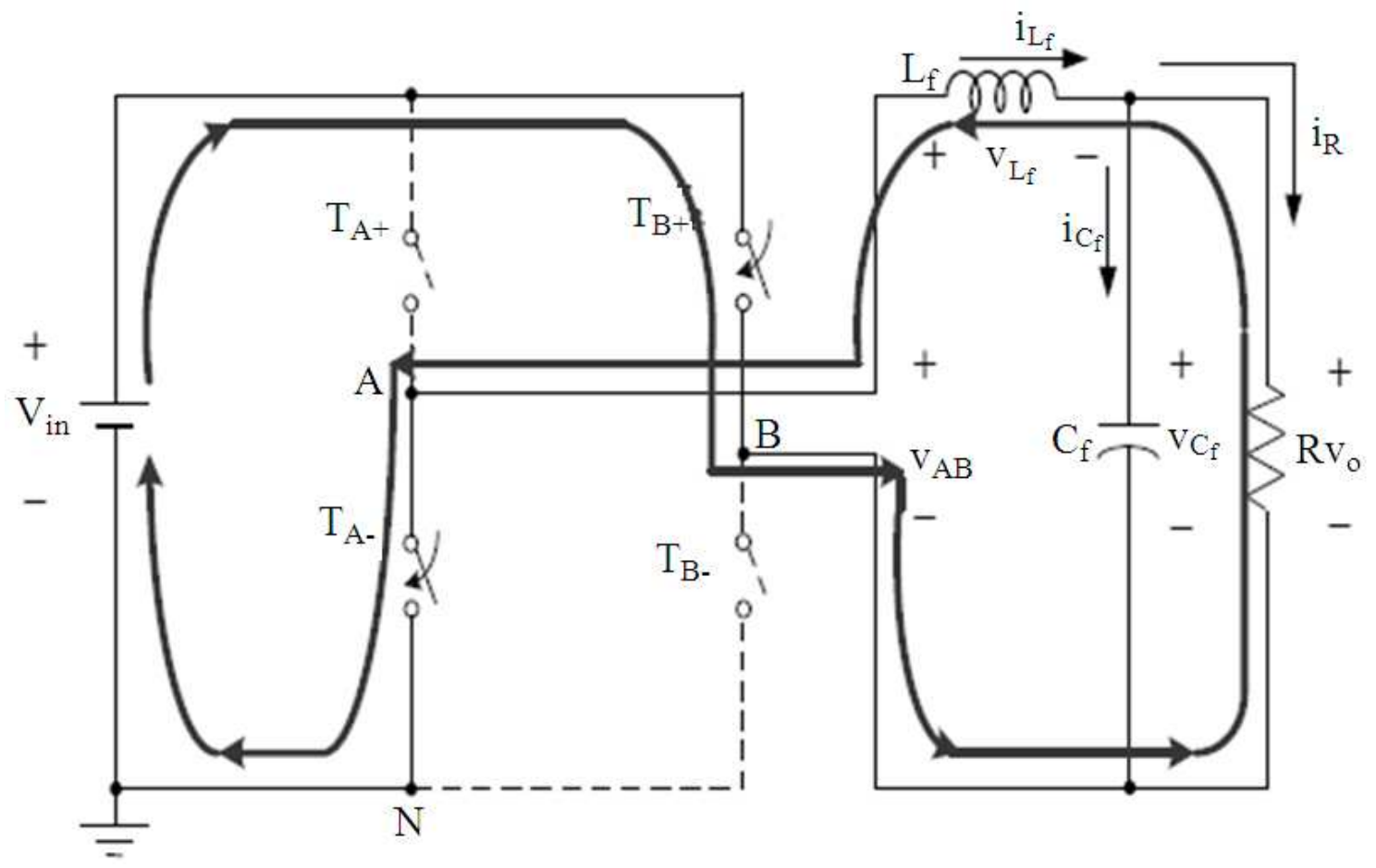

Fig. 3. Equivalent circuit of topology

$(2)$

Table 1. The Inverter system Parameters for Simulation

\begin{tabular}{ll}
\hline Circuit parameter & Range of parameter \\
\hline Load Resistance, $\mathrm{R}_{\mathrm{L}}$ & $\mathrm{R}_{\mathrm{L}}=10-50 \Omega$ \\
Filter Inductance, $\mathrm{L}_{\mathrm{f}}$ & $2 \mathrm{mH}$ \\
Filter Capacitance, $\mathrm{C}_{\mathrm{f}}$ & $500 \mu \mathrm{f}$ \\
$\begin{array}{l}\mathrm{DC} \text { input voltage, } \mathrm{V}_{\text {in }} \\
\text { Reference Voltage of }\end{array}$ & $15 \mathrm{~V}$ \\
sinusoidal $\mathrm{V}_{\text {ref }}$ and frequency & $5 \mathrm{~V}_{\text {peak }}, 60 \mathrm{~Hz}$ \\
Switch frequency, $\mathrm{f}_{\mathrm{s}}$ & $7.69 \mathrm{KHz}$ \\
PI Controller & $\mathrm{Kp}=19, \mathrm{~K}_{\mathrm{i}}=7.1$ \\
Divider resistance & $\mathrm{R}_{1}=6.4 \mathrm{~K} \Omega$ \\
$\mathrm{R}_{1}$ and $\mathrm{R}_{2}$ & $\mathrm{R}_{2}=3.2 \mathrm{~K} \Omega$ \\
\hline
\end{tabular}

Where:

$\mathrm{K}_{\mathrm{p}}=$ Proportional gain

$\mathrm{T}_{\mathrm{i}}=$ Integral time

The proportional action increases the loop gain and makes the system less sensitive to variations of system parameters. The integral action eliminates or reduces the steady state error. The integral action is adjusted by varying the integral time.
The Simulink block diagram of reduction of total harmonics in single phase inverter with PI controller is shown in Fig. 4.

Figure 5 demonstrates the effectiveness of PI controller for reducing voltage harmonics irrespective of Load variations.

Figure 6 shows the reduction of output harmonics by using PI controller exhibits reduced THD value and stable output.

\subsection{Simulink Block Diagram of Inverter using Fuzzy Logic Controller}

The Simulink block diagram of Reduction of Harmonics using single phase inverter is shown in Fig. 7. The objective of the system is to convert DC input voltage vin into a sinusoidal output voltage irrespective to the variation of load resistance $\mathrm{R}$.

Figure 8 shows the output voltage plotted against time. It is found that the controller acts very effectively and the THD value gets very much reduced for the change in load from $10 \Omega$ to $50 \Omega$.

Figure 9 shows the output current plotted against time. It is found that the controller acts very effectively and it reduces the harmonics irrespective of a variation of Load. 
Spencer Prathap Singh and Kesavan Nair / American Journal of Applied Sciences 10 (11): 1378-1385, 2013

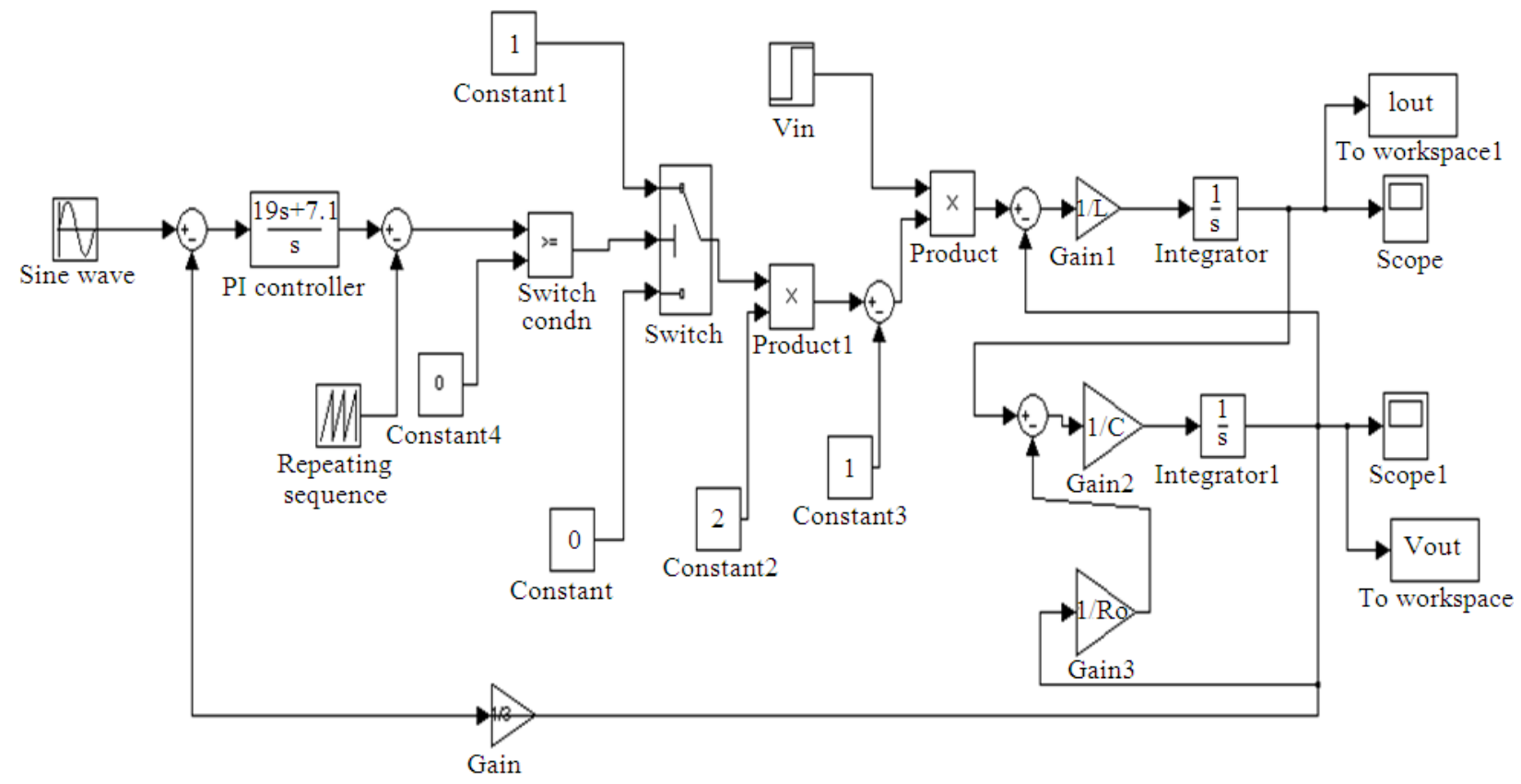

Fig. 4. Simulink model for the reduction of harmonics in 1-phase full bridge inverter using PI controller

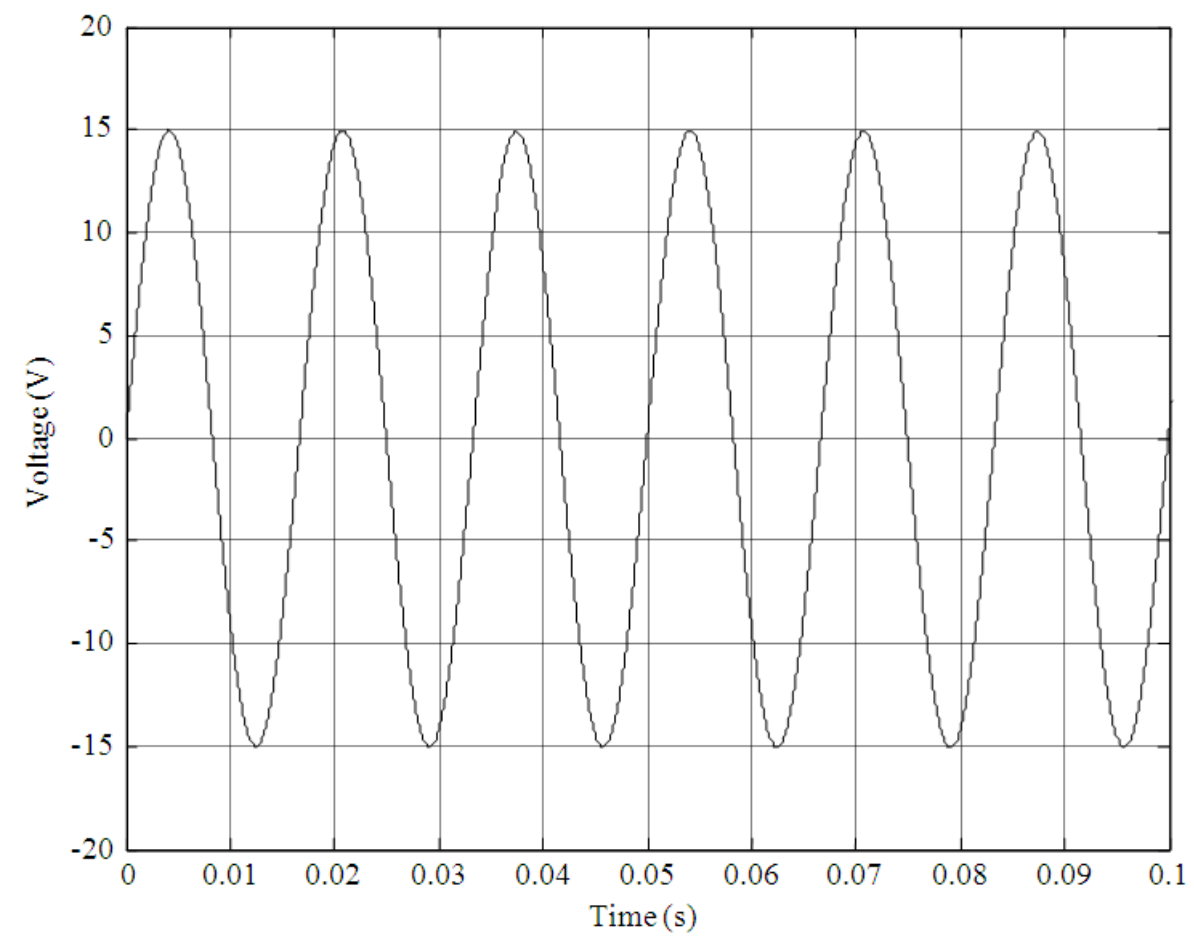

Fig. 5. Output voltage waveform of reduction of harmonics in 1-phase full bridge Inverter using PI controller by varying load resistance from $R=10 \Omega-50 \Omega$ 


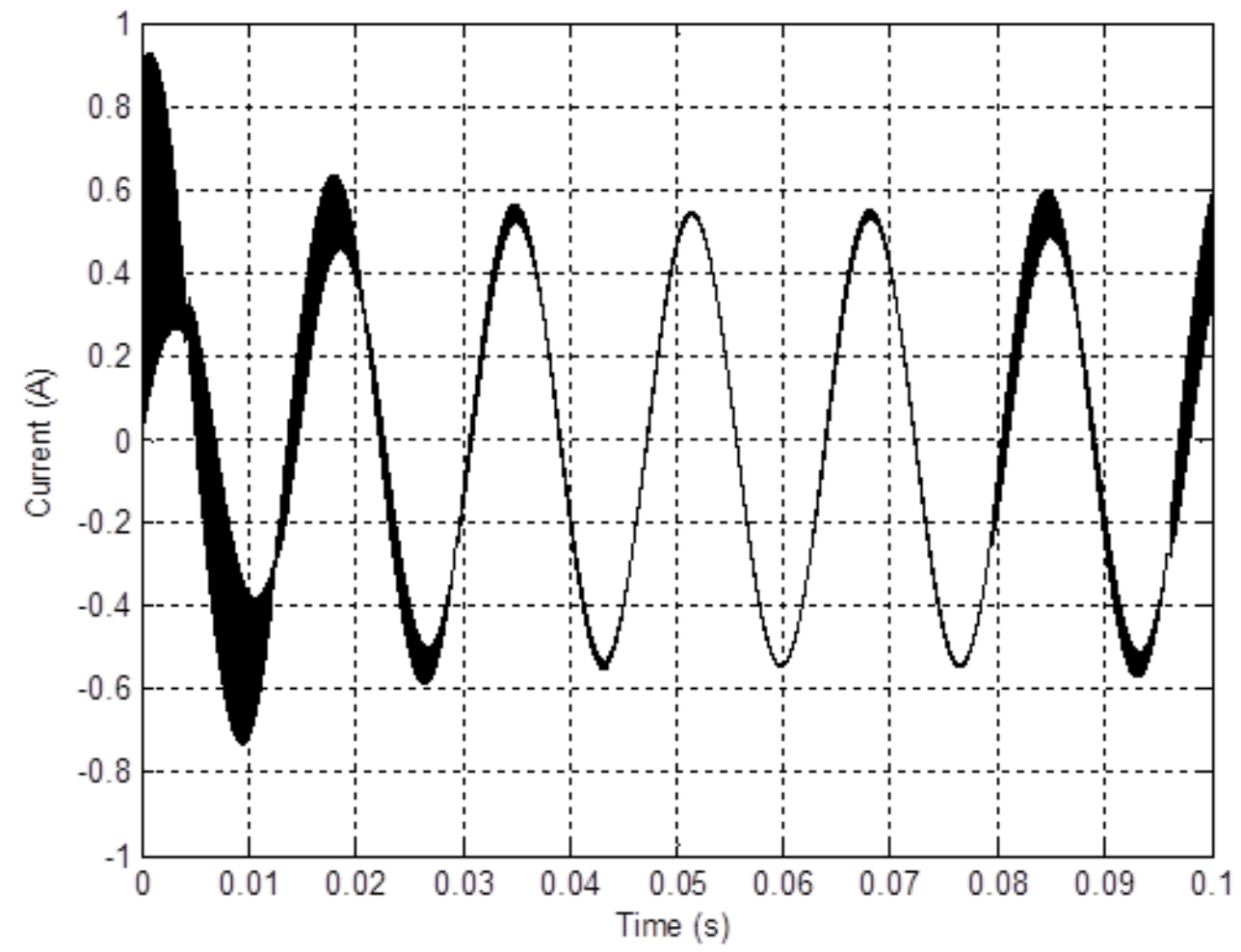

Fig. 6. Output current waveform of reduction of harmonics in 1-phase full bridge Inverter using PI controller by varying load resistance $\mathrm{R}=10 \Omega-50 \Omega$

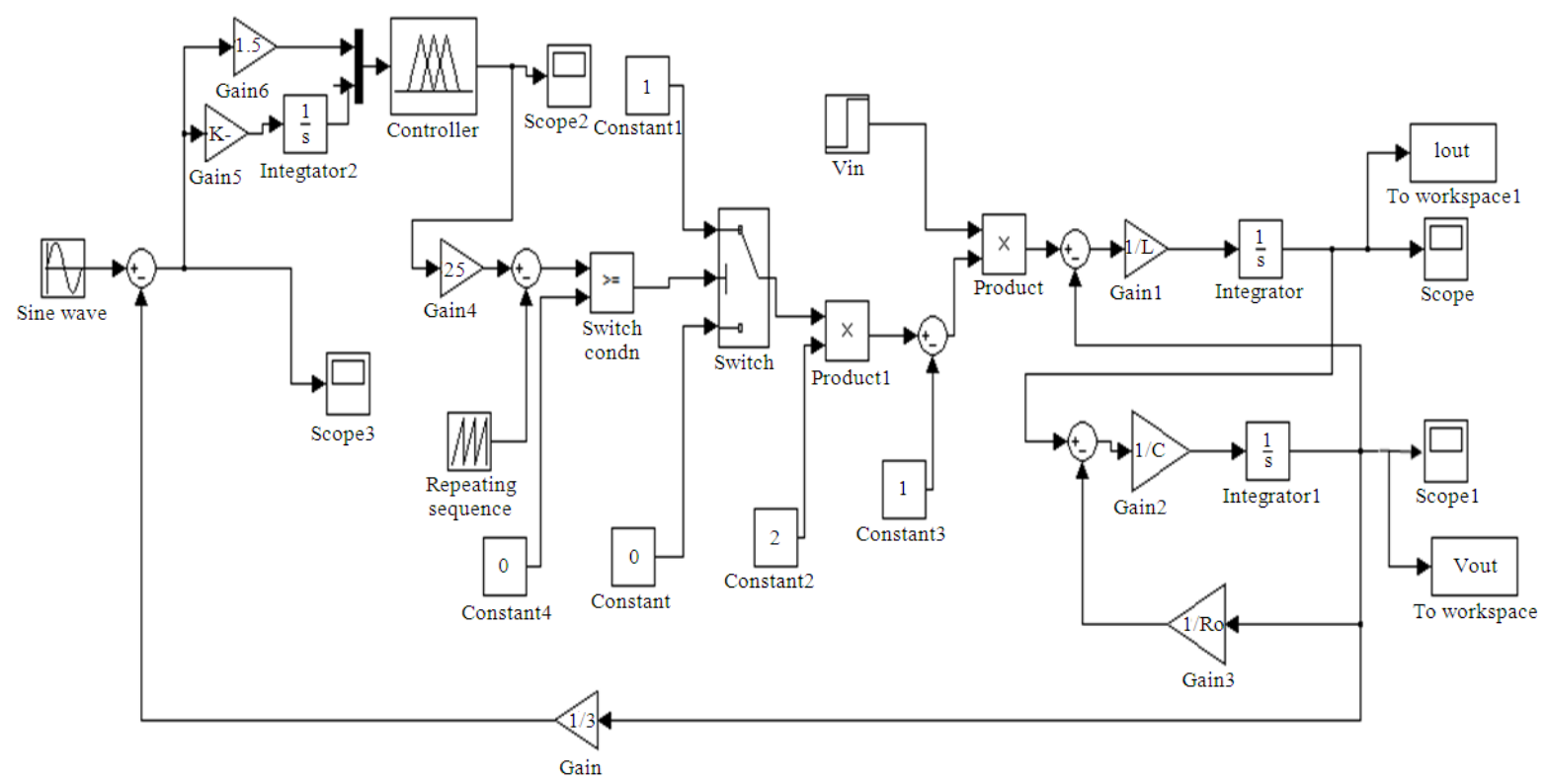

Fig. 7. Simulink Schematic of the proposed FLC Scheme 


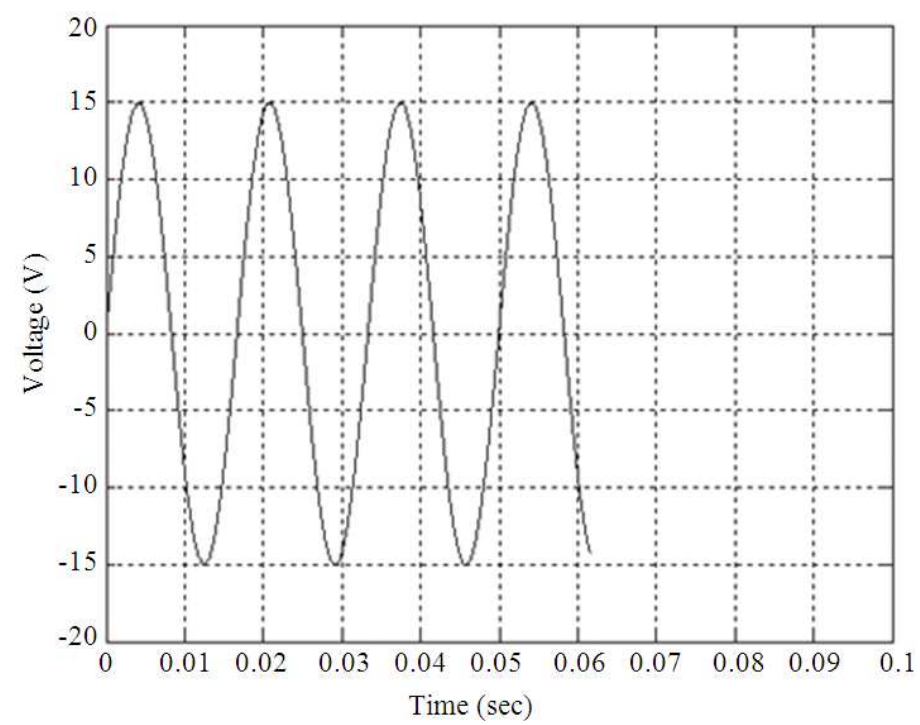

Fig. 8. Output Voltage waveform using Fuzzy controller subjected to a variation of Load from $10 \Omega$ to $50 \Omega$

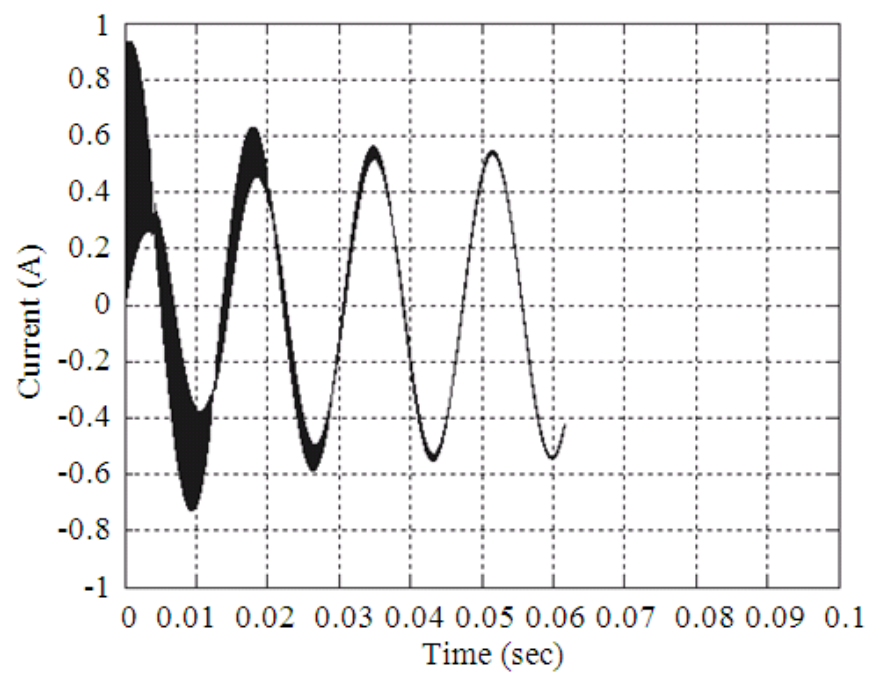

Fig. 9. Instantaneous Output current by Fuzzy controller subjected to a variation of load from $10 \Omega$ to $50 \Omega$

\section{CONCLUSION}

Reduction of harmonics in single phase inverter using PI and Fuzzy logic controllers has been described in this study. The Fuzzy logic controller gives an improved performance with reduction in THD value, compared with conventional PI controller. More over Fuzzy logic controller provides optimal performance on all operating condition of the system. Further work will be pursued incorporating more intelligent schemes in the controller so that the system performance may be improved.

\section{REFERENCES}

Hsieh, F.H., Chang, P.L. Y.S. Chen, H.K. Wang and J.C. Hwang, 2009. Fast-scale instability phenomena and chaotic control of voltage control single-phase full-bridge inverter via varying load resistance. Proceedings of the 4th IEEE Conference on Industrial Electronics and Applications, May 25-27, IEEE Xplore Press, Xi'an, pp: 3422- 3427. DOI: 10.1109/ICIEA.2009.5138837 
Korimi-Ghartemani, M. and M.R. Iravani, 2005. Measurement of harmonics/inter-harmonics of timevarying frequencies. IEEE Trans. Power Deliv., 20: 23-31. DOI: 10.1109/TPWRD.2004.837674(410)2

McNamara, D.M. A.K. Ziarani and T.H. Ortmeyer, 2007. A new technique of measurement of nonstationary harmonics. IEEE Trans. Power Deliv., 22: 387-395. DOI: 10.1109/TPWRD.2006.874622

Moo, C.S., N.Y. Chang and P.P. Mok, 1995. A digital measurement scheme for time-varying transient harmonics. IEEE Trans. Power Deliv., 10: 588-594. DOI: $10.1109 / 61.400874$

Moreno, V.M. and A. Pigazo, 2007. Modified FBD method in active power filters to minimize the line current harmonics. IEEE Trans. Power Deliv., 22: 735-736. DOI: 10.1109/TPWRD.2006.886769

Rahim, N.M.A. and J.E. Quaicoe, 1996. Analysis and design design of multiple feedback loop control strategy for single-phase voltage-source UPS inverter. IEEE Trans. Power Electron., 11: 532-541. DOI: $10.1109 / 63.506118$

Rech, C., H. Pinheiro, H.A. Groundling, H. Leaes and J.R. Pinheiro, 2003. A modified discrete control boul for UPS Applications. IEEE Trans. Power Deliv., 18: 1138-1145. DOI: 10.1109/TPEL.2003.816187
Ryan, M.J., W.E. Brumsickle and R.D. Lorenz, 1997. Control topology options for single-phase UPS inverters. IEEE Trans. Indus. Appli., 33: 493-501. DOI: $10.1109 / 28.568015$

Selvajyothi, K. and P.A. Janakiraman, 2010. Reduction of voltage harmonics in single phase inverters using composite observers. IEEE Trans. Power Deliv., 25: 1045-1057. DOI: 10.1109/TPWRD.2009.2035917

Tai, T.L. and J.S. Chen, 2002. UPS inverter design using discrete-time sliding-mode control scheme. IEEE Trans. Indus. Electron., 49: 67-75. DOI: $10.1109 / 41.982250$

Villarreal-Ortiz, R.A., M. Hernandez-Angeles, C.R. Fuerte-Esquivel and R.O. Villanueva-Chavez, 2005. Centroid PWM technique for inverter harmonics elimination. IEEE Trans. Power Deliv., 20: 12091210. DOI: 10.1109/TPWRD.2004.839738

Zobaa, A.F., 2006. Voltage Harmonic reduction for randomly time-varying source characteristics and voltage harmonics. IEEE Trans. Power Deliv., 21: 816-822. DOI: 10.1109/TPWRD.2005.864043 